\title{
REVIEW
}

\section{Therapeutic hypothermia: is it effective for non-VF/VT cardiac arrest?}

\author{
Claudio Sandroni*, Fabio Cavallaro, Massimo Antonelli \\ This article is one of ten reviews selected from the Annual Update in Intensive Care and Emergency Medicine 2013 and co-published as a series \\ in Critical Care. Other articles in the series can be found online at http://ccforum.com/series/annualupdate2013. Further information about the \\ Annual Update in Intensive Care and Emergency Medicine is available from http://www.springer.com/series/8901.
}

\section{Introduction}

Sudden cardiac death represents a major health problem. In adults, the prevalence of out-of-hospital cardiac arrest (OHCA) attended by the emergency medical services (EMS) ranges from 52 to 112 per 100,000 person-years in developed countries [1], whereas the prevalence of adult in-hospital cardiac arrest (IHCA) ranges from 1 to 5 per 1,000 patient admissions [2].

Mortality from cardiac arrest exceeds $90 \%$ in OHCA $[1,3]$ and $70 \%$ in most studies on IHCA [4-6]. Patients who have a shockable rhythm, i. e., ventricular fibrillation (VF) or pulseless ventricular tachycardia (VT), on initial electrocardiogram (EKG) have a consistently higher survival than those whose initial cardiac rhythm is nonshockable, i. e., asystole or pulseless electrical activity (PEA).

More than two-thirds of initially resuscitated patients die before hospital discharge $[7,8]$. The major causes of hospital mortality are post-resuscitation brain and myocardial dysfunction $[9,10]$. Mild therapeutic hypothermia can reduce the severity of post-resuscitation brain injury and improve survival in patients who remain comatose after resuscitation from cardiac arrest. In 2002, two randomized clinical trials showed improved neurological outcome $[11,12]$ in a total of 350 comatose adults resuscitated from OHCA who were cooled to $32-34{ }^{\circ} \mathrm{C}$ for 12-24 hours shortly after recovery of spontaneous circulation. The largest of these trials [12] also showed a significant reduction in mortality within six months in patients treated with mild therapeutic hypothermia. Both these trials included only patients who had VF/VT as the initial rhythm.

Based on these results, subsequently confirmed by a meta-analysis [13], the International Liaison Committee

\footnotetext{
*Correspondence: sandroni@rm.unicatt.it

Department of Anesthesiology and Intensive Care, Catholic University School of Medicine, Largo Agostino Gemelli 8, 00168 Rome, Italy
}

on Resuscitation (ILCOR) recommended in 2003 the use of mild therapeutic hypothermia for all comatose survivors after OHCA due to VF/VT [14]; this recommendation was confirmed in the current 2010 Guidelines for Cardiopulmonary Resuscitation [15]. However, only $25-30 \%$ of OHCA patients have VF/VT as the initial recorded cardiac rhythm [1], and this percentage has decreased in recent years $[16,17]$, partly because of the advent of implantable cardioverter-defibrillators for the prevention and treatment of patients at risk of lethal arrhythmias [18]. The prevalence of VF/VT rhythms in IHCA does not exceed 25-30\% either [2]. For the remaining $70-75 \%$ of patients who undergo cardiac arrest with non-VF/VT rhythms, indications for receiving therapeutic hypothermia after resuscitation are less clear.

\section{Hypothermia for non-VF/VT cardiac arrest}

The evidence on whether use of mild therapeutic hypothermia could improve prognosis in comatose patients resuscitated from non-VF/VT cardiac arrest is sparse. We identified 15 observational studies (Table 1) and 2 randomized trials.

\section{Randomized clinical trials}

Use of mild therapeutic hypothermia for the treatment of patients resuscitated from non-VF/VT cardiac arrest has been described in two randomized trials, even though neither was specifically designed to assess the benefit of mild therapeutic hypothermia in this patient population. One trial was a feasibility study on a helmet device for inducing hypothermia after resuscitation [19], the other examined the effect of isovolemic high-volume hemofiltration alone or combined with mild therapeutic hypothermia to improve survival after cardiac arrest [20]. These trials included a total of only 44 patients with nonVF/VT rhythms. Within this small subgroup, patients treated with mild therapeutic hypothermia had a higher survival rate at six months than did controls $(5 / 22$ 
Table 1. Characteristics of 15 observational studies including data on use of mild therapeutic hypothermia in patients with non-ventricular fibrillation/ventricular tachycardia (VF/VT) cardiac arrest

\begin{tabular}{|c|c|c|c|c|c|c|c|c|c|}
\hline \multirow[b]{2}{*}{ Author [Reference] } & \multirow[b]{2}{*}{ Arrest location } & \multirow[b]{2}{*}{ Patients } & \multicolumn{2}{|c|}{ Non-VF/VT } & \multirow{2}{*}{$\begin{array}{l}\text { Initiation of } \\
\text { hypothermia }\end{array}$} & \multirow{2}{*}{$\begin{array}{l}\text { Cooling } \\
\text { method }\end{array}$} & \multirow{2}{*}{$\begin{array}{l}\text { Control } \\
\text { group }\end{array}$} & \multirow{2}{*}{$\begin{array}{l}\text { Definition } \\
\text { of poor } \\
\text { outcome }\end{array}$} & \multirow{2}{*}{$\begin{array}{l}\text { Length of } \\
\text { follow-up }\end{array}$} \\
\hline & & & Total & Cooled & & & & & \\
\hline Holzer 2006 [27] & Mixed (OHCA 67\%) & 1,038 & 534 & 28 & In-hospital & Internal & Concurrent & CPC 3-5 & 30 days \\
\hline Oddo 2006 [21] & $\mathrm{OHCA}$ & 109 & 23 & 12 & In-hospital & External & Historical & CPC 3-5 & Discharge \\
\hline Heer 2007 [26] & Mixed & 76 & 18 & 10 & In-hospital & Internal & Historical & NA & Discharge \\
\hline Sunde 2007 [29] & $\mathrm{OHCA}$ & 119 & 15 & 6 & In-hospital & Mixed & Historical & CPC 3-5 & Discharge \\
\hline Arrich 2007 [23] & Mixed (OHCA $83 \%)$ & 587 & 197 & 124 & In-hospital & Mixed & Concurrent & CPC 3-5 & Discharge \\
\hline Rittenberger 2008 [38] & Mixed (OHCA $56 \%)$ & 241 & 81 & 42 & In-hospital & Mixed & Concurrent & $\begin{array}{l}\text { Discharged to } \\
\text { a nursing home }\end{array}$ & Discharge \\
\hline Storm 2008 [28] & $\mathrm{OHCA}$ & 126 & 49 & 18 & In-hospital & Mixed & Historical & CPC 3-5 & Discharge \\
\hline Don 2009 [24] & $\mathrm{OHCA}$ & 491 & 313 & 122 & In-hospital & External & Historical & CPC 2-5 & Discharge \\
\hline Whitfield 2009 [30] & $\mathrm{OHCA}$ & 123 & 28 & 15 & Pre/In-hospital & Mixed & Historical & $\begin{array}{l}\text { Discharged to } \\
\text { a nursing home }\end{array}$ & Discharge \\
\hline Gaieski 2009 [39] & $\mathrm{OHCA}$ & 38 & 18 & 9 & In-hospital & Mixed & Historical & CPC 3-5 & Discharge \\
\hline Bro-Jeppesen 2009 [25] & $\mathrm{OHCA}$ & 156 & 48 & 27 & Pre/In-hospital & Mixed & Historical & CPC 3-5 & 6 months \\
\hline Derwall 2009 [37] & $\mathrm{OHCA}$ & 68 & 28 & 13 & In-hospital & Mixed & Concurrent & CPC 3-5 & 14 days \\
\hline Dumas 2011 [33] & $\mathrm{OHCA}$ & 1,145 & 437 & 261 & In-hospital & External & Historical & CPC 3-5 & Discharge \\
\hline Storm 2012 [34] & Mixed (OHCA $73 \%)$ & 387 & 175 & 87 & In-hospital & Mixed & Historical & CPC 1-2 & 90 days \\
\hline Lundbye 2012 [35] & Mixed (OHCA 52\%) & 100 & 100 & 52 & In-hospital & Internal & Historical & CPC 3-5 & Discharge \\
\hline
\end{tabular}

OHCA: out-of-hospital cardiac arrest; CPC: Cerebral Performance Category.

vs. $2 / 22$; risk ratio $[R R]$ for mortality $0.85[0.65-1.11]$ $\mathrm{p}=0.24)$.

\section{Observational studies}

A series of observational studies evaluated the effects of mild therapeutic hypothermia in non-VF/VT patients (Table 1). In a retrospective analysis from Oddo et al. [21] of a database on the implementation of mild therapeutic hypothermia in an intensive care unit (ICU), the rates of good neurological outcome (Cerebral Performance Category [CPC] 1-2 [22]) in a small subgroup of patients resuscitated from non-VF/VT arrest and treated with mild therapeutic hypothermia was not significantly better than that of historical controls $(2 / 12$ vs. $1 / 11 ; \mathrm{p}=0.99)$.

In 2007, the results of the European Resuscitation Council Hypothermia After Cardiac Arrest Registry (HACA-R) were published [23]. This multicenter observational study included data from 19 participating centers on 587 patients resuscitated from cardiac arrest, around $18 \%$ of which had occurred in hospital. The nonFV/VT subgroup included 197 subjects, 124 (63\%) of whom were treated using mild therapeutic hypothermia. The rate of survival to hospital discharge was significantly higher in mild therapeutic hypothermia-treated patients
(45/124 (35\%) vs. $14 / 73(19 \%) ; \mathrm{p}=0.023)$. The rate of the combined endpoint of death $(\mathrm{CPC}=5)$ and poor neurological outcome (CPC 3-4) was also lower - although not significantly - in the mild therapeutic hypothermia group $(89 / 124$ [71 \%] vs. 59/73 [81\%] $\mathrm{p}=0.21)$. In this study, only univariate analysis was performed, so no correction was made for pre- and intra-arrest potential confounders. Another limitation was the risk of selection bias, because the choice of using hypothermia in a given patient was left to the discretion of the treating physician.

In 2009, a large, retrospective study by Don et al. [24] on implementation of mild therapeutic hypothermia in a community hospital during a five year-period was published. The study included a total of 491 patients with OHCA with all rhythms, of whom 313 (74\%) had nonVF/VT cardiac arrest. Patients enrolled after implementation of the therapeutic hypothermia protocol were compared with historical controls. Results showed that whereas in patients with VF/VT the hypothermia period was associated with significantly higher rates of survival to hospital discharge and favorable neurological outcome as compared to the pre-hypothermia period $(44 / 81$ [54.3\%] vs. $36 / 93$ [38.7\%]; $p=0.04$ and 28/81 [34.6\%] vs. $14 / 93[15 \%] ; \mathrm{p}=0.01$, respectively), there were no 
significant improvements in patients resuscitated from non-VF/VT rhythms $(26 / 122$ [21 \%] vs. 37/191 [19\%], $\mathrm{p}=0.78$ and $14 / 122[11 \%]$ vs. $17 / 191[9 \%], \mathrm{p}=0.82$, respectively). Moreover, results of multivariable analysis showed a slight trend towards a worse outcome for the mild therapeutic hypothermia period in patients with non-VF/VT rhythms (favorable neurological outcome odds ratio [OR] $0.82[0.41-1.60]$; survival to discharge OR 0.92 [0.37-2.32]).

Other smaller observational studies on mild therapeutic hypothermia were carried out between 2006 and 2009 [25-30]. None of these studies was designed to specifically investigate the association between mild therapeutic hypothermia and prognosis of non-VF/VT rhythms. The majority of these studies documented a non-significant trend towards better outcome when mild therapeutic hypothermia was used in patients with non-VF/VT cardiac arrest.

A recent systematic review and meta-analysis by Kim et al. [31] evaluated the two randomized studies reported above and 12 non-randomized studies for a total of 1,336 non-VF/VT patients, 412 (30.8\%) of whom were treated using mild therapeutic hypothermia. The quality of evidence was assessed using the GRADE methodology [32]. The results showed that the quality of evidence in all studies was very low. Most of the studies had substantial risks of bias and 9/12 had a high degree of imprecision, because of their small sample size. Pooled data from the two small randomized studies showed a non-significant trend toward a lower 6-month mortality with mild therapeutic hypothermia (RR 0.85 [0.65-1.11]). Metaanalysis of the 12 observational studies showed a significant reduction in hospital mortality (RR 0.84 [0.78-0.92]) and a non-significant trend towards better neurological outcome (RR for poor neurological outcome 0.95 [0.901.01]) after mild therapeutic hypothermia. The authors concluded that mild therapeutic hypothermia was associated with reduced in-hospital mortality for adult patients resuscitated from non-shockable cardiac arrest, but also suggested caution in interpreting the results, given a substantial risks of bias and the low quality of the evidence.

\section{Results of the most recent studies}

Three very recent studies that were not included in the systematic review by Kim et al. [31] reported conflicting results on the potential benefit of mild therapeutic hypothermia in patients with non-VF/VT cardiac arrest. A first study by Dumas et al. [33] reported data from a prospective French database including 1,145 OHCA patients, 437 of whom were non-VF/VT patients. The association between mild therapeutic hypothermia and good neurological outcome at discharge (CPC 1 or 2) was quantified by logistic regression analysis. Mild therapeutic hypothermia was induced in 457/708 (65\%) patients with VF/VT and in 261/437 (60\%) with non-VF/VT. After adjustment for confounders, the results showed that whereas mild therapeutic hypothermia was associated with a significantly better neurological outcome at discharge in VF/VT patients, there was a trend towards a worse outcome in non-VF/VT patients (OR 1.90 [1.18$3.06]$ vs. $0.71[0.37-1.36])$.

Another prospective single-center observational study was conducted by Storm et al. [34] in a university hospital setting with historical controls. The paper enrolled 387 consecutive patients with all rhythms who had been admitted to the ICU after cardiac arrest. Mild therapeutic hypothermia was induced in 201 patients (87 with nonVF/VT), who were compared with 186 historical controls (88 with non-VF/VT). Univariate analysis showed a nonsignificant trend towards better neurological outcome in non-VF/VT patients treated with mild therapeutic hypothermia (24/87 [27.8\%] vs 16/88 [18\%], p = 0.17). On Cox regression analysis, however, the risk for poor neurological outcome at discharge in the two groups was almost identical (hazard ratio [HR] 0.98 [0.53-1.50]). KaplanMeier analysis revealed no differences in 90-day survival with or without mild therapeutic hypothermia $(\mathrm{p}=0.82)$.

Finally, a recent small single-center observational study by Lundbye et al. [35] compared neurological outcome and survival at hospital discharge in 52 non-VF/VT cardiac arrest patients treated using mild therapeutic hypothermia compared with 48 historical controls who did not receive mild therapeutic hypothermia. In contrast with the previous two studies, the rates of good neurological outcome $(15 / 52$ [29\%] vs. $6 / 48[13 \%] ; \mathrm{p}=0.021)$ and survival to discharge (20/52 [38 \%] vs. 9/48 [19\%]; $\mathrm{p}=0.03$ ) were significantly higher in patients treated with mild therapeutic hypothermia. These results were confirmed after controlling for confounders using binomial logistic regression (OR 4.35 [1.10-17.24], $\mathrm{p}=0.04$ and OR 5.65 [1.66-19.23], $\mathrm{p}=0.006$, respectively).

The Forest plots in Fig. 1a, b summarize the results of 12 observational studies reporting survival to discharge (1,581 patients, Fig. 1a) and of 13 observational studies reporting neurological outcome (1,998 patients, Fig. 1b). Data pooled according to a fixed effect model show a significant reduction in the $R R$ for hospital mortality $(0.88$ [0.82-0.95]) and a smaller but significant reduction in RR for poor neurological outcome $(0.95$ [0.90-0.99]) in patients treated using mild therapeutic hypothermia. However, in spite of pooled results favoring treatment, the effect is not consistent, with large studies showing increased RR for poor neurological outcome associated with use of mild therapeutic hypothermia [33] (Fig. 1b).

In comparison with the results of randomized trials in VF/VT patients [36], analysis of the available evidence shows that use of mild therapeutic hypothermia in 
comatose patients resuscitated from non-VF/VT cardiac arrest is associated with a small effect size, particularly as regards neurological outcome, with several studies $[24,30,33,37,38]$ suggesting no effect or even a possible harm from mild therapeutic hypothermia. There are many possible explanations for this observation. One explanation could be that patients who undergo a cardiac arrest with non-VF/VT rhythms represent a more heterogeneous population as compared to those with a VF/VT arrest. Sudden death due to VF/VT is usually the result of cardiac causes, such as arrhythmia or acute myocardial ischemia, whereas non-VF/VT rhythms (asystole or PEA) have a wider variety of causes, such as hypoxia, hypovolemia, sepsis, pulmonary thromboembolism, or cardiac tamponade. These causes are often associated with major comorbidities, which could reduce the chances of patient survival after resuscitation, regardless of the protective effect of mild therapeutic hypothermia. Moreover, cardiac arrest from these causes is often preceded by generalized hypoxia or hypoperfusion, which may further worsen cerebral anoxic damage. Finally, since asystole represents the final evolution of all cardiac arrest rhythms, its presence may indicate a long collapse-to-resuscitation interval and/or poor or absent bystander resuscitation, both of which are associated with a high risk of irreversible neurological damage. In some studies, therefore, non-VF/VT patients could have been simply too ill to benefit from mild therapeutic hypothermia.

Heterogeneity observed in study results may also be explained by differences in case mix and in cooling protocols. For example, some studies included only OHCA patients, whereas others included both IHCA and OHCA (see Table 1). Two of the studies that documented lack of benefit from mild therapeutic hypothermia used the external surface cooling method, which may require longer times to achieve the target temperature than with intravascular cooling.

Finally, apart from two trials with minimal sample sizes, all the published studies on mild therapeutic hypothermia for non-VF/VT arrest are observational. This makes controlling of confounders extremely difficult to achieve and introduces further sources of bias. Studies in which the control group was represented by concurrent patients not treated using mild therapeutic hypothermia are prone to selection bias, and in those with historical 
controls, the results may reflect secular trends in patient or disease characteristics or changes in resuscitation practice rather than the effect of the study intervention.

To be correctly addressed, the question as to whether mild therapeutic hypothermia may be beneficial in patients with asystole or PEA as the initial cardiac rhythm will require a purposely designed, high-quality randomized controlled trial. However, in order to demonstrate an increase in survival from $25 \%$ to $30 \%$ with a 0.05 risk of a type- 1 error (alpha) and a 0.20 risk of type-II error (beta) using univariate analysis, a minimum of 1,100 patients resuscitated from non-VF/VT would be required. Such a large sample size would be difficult to collect, considering that only about $10 \%$ of patients resuscitated from cardiac arrest of all rhythms survive to hospital admission [8]. Moreover, this trial may even raise ethical issues, since pooled results from observational studies suggest a modest but significant benefit from mild therapeutic hypothermia in non-FV/VT cardiac arrests.

\section{Conclusions}

Non-VF/VT are the most common initial cardiac rhythms recorded in both in-hospital and out-of-hospital cardiac arrests. Unfortunately, patients with non-VF/ VT rhythms also represent the majority of those who die despite resuscitation, and interventions able to improve the prognosis of this patient category are eagerly awaited. Whereas mild therapeutic hypothermia has been consistently demonstrated to improve outcomes after VF/VT cardiac arrest, its use in patients with non-VF/VT arrest has produced conflicting results. Pooled data from available studies show that the use of mild therapeutic hypothermia for 24 hours in comatose patients resuscitated from non-VF/VT arrest was associated with a $15 \%$ reduction in hospital mortality and with a minimal, albeit significant improvement in neurological outcome at discharge. The quality of evidence supporting these results, however, is very poor, since it is based almost exclusively on observational studies, most of which were not specifically designed to evaluate the benefit of mild therapeutic hypothermia in non-VF/VT patients. Randomized controlled trials of adequate sample size are necessary to address this question.

\section{Competing interests}

The authors declare that they have no competing interests.

\section{List of abbreviations used}

CPC: cerebral performance category; EKG: electrocardiogram; EMS: emergency medical services; HACA-R: Hypothermia After Cardiac Arrest Registry; HR: hazard ratio; ICU: intensive care unit; IHCA: in-hospital cardiac arrest; ILCOR: International Liaison Committee on Resuscitation; OHCA: out-of-hospital cardiac arrest; PEA: pulseless electrical activity; RR: risk ratio; VF: ventricular fibrillation; VT: ventricular tachycardia.

Published: 19 March 2013
References

1. Berdowski J, Berg RA, Tijssen JG, Koster RW: Global incidences of out-ofhospital cardiac arrest and survival rates: Systematic review of 67 prospective studies. Resuscitation 2011,81:1479-1487.

2. Sandroni C, Nolan J, Cavallaro F, Antonelli M: In-hospital cardiac arrest: incidence, prognosis and possible measures to improve survival. Intensive Care Med 2007, 33:237-245.

3. Nichol G, Thomas E, Callaway CW, Hedges J, Powell JL, Aufderheide TP, Rea T, Lowe R, Brown T, Dreyer J, Davis D, Idris A, Stiell I, Resuscitation Outcomes Consortium Investigators: Regional variation in out-of-hospital cardiac arrest incidence and outcome. JAMA 2008, 300:1423-1431.

4. Nadkarni VM, Larkin GL, Peberdy MA, Carey SM, Kaye W, Mancini M, Nichol G, Lane-Truitt T, Potts J, Ornato JP, Berg RA, National Registry of

Cardiopulmonary Resuscitation Investigators: First documented rhythm and clinical outcome from in-hospital cardiac arrest among children and adults. JAMA 2006, 295:50-57.

5. Peberdy MA, Kaye W, Ornato JP, Larkin GL, Nadkarni V, Mancini ME, Berg RA, Nichol G, Lane-Truitt T: Cardiopulmonary resuscitation of adults in the hospital: a report of 14,720 cardiac arrests from the National Registry of Cardiopulmonary Resuscitation. Resuscitation 2003, 58:297-308.

6. Sandroni C, Ferro G, Santangelo S, Tortora F, Mistura L, Cavallaro F, Caricato A, Antonelli M: In-hospital cardiac arrest: survival depends mainly on the effectiveness of the emergency response. Resuscitation 2004, 62:291-297.

7. Nolan JP, Laver SR, Welch CA, Harrison DA, Gupta V, Rowan K: Outcome following admission to UK intensive care units after cardiac arrest: a secondary analysis of the ICNARC Case Mix Programme Database. Anaesthesia 2007, 62:1207-1216.

8. Stiell IG, Wells GA, Field BJ, Spaite DW, De Maio VJ, Ward R, Munkley DP, Lyver MB, Luinistra LG, Campeau T, Maloney J, Dagnone E: Improved out-ofhospital cardiac arrest survival through the inexpensive optimization of an existing defibrillation program: OPALS study phase II. Ontario Prehospital Advanced Life Support. JAMA 1999, 281:1175-1181.

9. Laver S, Farrow C, Turner D, Nolan J: Mode of death after admission to an intensive care unit following cardiac arrest. Intensive Care Med 2004, 30:2126-2128

10. Nolan JP, Neumar RW, Adrie C, Akibi M, Berg RA, Böttinger BW, Callaway C, Clark RS, Geocardin RG, Jauch EC, Kern KB, Laurent I, Longstreth WT, Merchan RM, Morley P, Morrison LJ, Nakarni V, Peberdy MA, Rivers EP, Rodriguez-Nunez A, Sellke FW, Spaulding C, Sunde K, Hoek TV: Post-cardiac arrest syndrome: epidemiology, pathophysiology, treatment, and prognostication. A Scientific Statement from the International Liaison Committee on Resuscitation; the American Heart Association Emergency Cardiovascular Care Committee; the Council on Cardiovascular Surgery and Anesthesia; the Council on Cardiopulmonary, Perioperative, and Critical Care; the Council on Clinical Cardiology; the Council on Stroke. Resuscitation 2008, 79:350-379.

11. Bernard SA, Gray TW, Buist MD, Jones BM, Silvester W, Gutteridge G, Smith K: Treatment of comatose survivors of out-of-hospital cardiac arrest with induced hypothermia. N Engl J Med 2002, 346:557-563.

12. The HACA study group: Mild therapeutic hypothermia to improve the neurologic outcome after cardiac arrest. N Engl J Med 2002, 346:549-556.

13. Holzer M, Bernard SA, Hachimi-Idrissi S, Roine RO, Sterz F, Mullner M: Hypothermia for neuroprotection after cardiac arrest: systematic review and individual patient data meta-analysis. Crit Care Med 2005, 33:414-418.

14. Nolan JP, Morley PT, Hoek TL, Hickey RW: Therapeutic hypothermia after cardiac arrest. An advisory statement by the Advancement Life support Task Force of the International Liaison committee on Resuscitation. Resuscitation 2003, 57:231-235.

15. Peberdy MA, Callaway CW, Neumar RW, Geocardin RG, Zimmerman JL, Donnino M, Garbielli A, Silvers SM, Zaritsky AL, Merchant R, Vanden HoekTL, Kronick SL: Part 9: post-cardiac arrest care: 2010 American Heart Association Guidelines for Cardiopulmonary Resuscitation and Emergency Cardiovascular Care. Circulation 2010, 122:S768-S786.

16. Agarwal DA, Hess EP, Atkinson EJ, White RD: Ventricular fibrillation in Rochester, Minnesota: experience over 18 years. Resuscitation 2009, 80:1253-1258.

17. Cobb LA, Fahrenbruch CE, Olsufka M, Copass MK: Changing incidence of out-of-hospital ventricular fibrillation. JAMA 2002, 288:3008-3013.

18. Hulleman M, Berdowski J, de Groot JR, van Dessel PF, Borleffs CJ, Blom MT Bardai A, de Cock CC, Tan HL, Tijssen JG, Koster RW: Implantable cardioverter-defibrillators have reduced the incidence of resuscitation for 
out-of-hospital cardiac arrest caused by lethal arrhythmias. Circulation 2012, 126:815-821.

19. Hachimi-Idrissi S, Corne L, Ebinger G, Michotte Y, Huyghens L: Mild hypothermia induced by a helmet device: a clinical feasibility study. Resuscitation 2001, 51:275-281.

20. Laurent I, Adrie C, Vinsonneau C, Cariou A, Chich JD, Ohanessian A, Spaulding C, Carli P, Dhainaut JF, Monchi M: High-volume hemofiltration after out-ofhospital cardiac arrest: a randomized study. J Am Coll Cardiol 2005, 46:432-437

21. Oddo M, Schaller MD, Feihl F, Ribordy V, Liaudet L: From evidence to clinical practice: effective implementation of therapeutic hypothermia to improve patient outcome after cardiac arrest. Crit Care Med 2006, 34:1865-1873.

22. Brain Resuscitation Clinical Trial I Study Group: A randomized clinical study of cardiopulmonary-cerebral resuscitation: design, methods, and patient characteristics. Am J Emerg Med 1986, 4:72-86.

23. Arrich J: Clinical application of mild therapeutic hypothermia after cardiac arrest. Crit Care Med 2007, 35:1041-1047.

24. Don CW, Longstreth Jr WT, Maynard C, Olsufka M, Nichol G, Ray T, Kupchik N, Deem S, Copass MK, Cobb LA, Kim F: Active surface cooling protocol to induce mild therapeutic hypothermia after out-of-hospital cardiac arrest: a retrospective before-and-after comparison in a single hospital. Crit Care Med 2009, 37:3062-3069.

25. Bro-Jeppesen J, Kjaergaard J, Horsted TI, Wanscher MC, Nielsen SL, Rasmussem LS, Hassager C: The impact of therapeutic hypothermia on neurological function and quality of life after cardiac arrest. Resuscitation 2009, 80:171-176.

26. Heer $\mathrm{C}$ : Hypothermia after cardiac arrest - experiences in routine use on a medical intensive care unit. Intensivmedizin und Notfallmedizin 2007, 44:303-307.

27. Holzer M, Mullner M, Sterz F, Robak O, Kligel A, Losert H, Sodeck G, Uray T, Zeiner A, Laggner AN: Efficacy and safety of endovascular cooling after cardiac arrest: cohort study and Bayesian approach. Stroke 2006, 37:1792-1797.

28. Storm C, Steffen I, Schefold JC, Krueger A, Oppert M, Jörres A, Hasper D: Mild therapeutic hypothermia shortens intensive care unit stay of survivors after out-of-hospital cardiac arrest compared to historical controls. Crit Care 2008, 12:R78.

29. Sunde K, Pytte M, Jacobsen D, Mangschau A, Jensen LP, Smedsrud C, Draegni T, Steen PA: Implementation of a standardised treatment protocol for post resuscitation care after out-of-hospital cardiac arrest. Resuscitation 2007, 73:29-39

30. Whitfield AM, Coote S, Ernest D: Induced hypothermia after out-of-hospital cardiac arrest: one hospital's experience. Crit Care Resusc 2009, 11:97-100.
31. Kim YM, Yim HW, Jeong SH, Klem ML, Callaway CW: Does therapeutic hypothermia benefit adult cardiac arrest patients presenting with nonshockable initial rhythms?: A systematic review and meta-analysis of randomized and non-randomized studies. Resuscitation 2012, 83:188-196.

32. Guyatt GH, Oxman AD, Vist GE, Kunz R, Falck-Ytter T, Alonso-Coello P, Schünemann HJ, GRADE Working Group: GRADE: an emerging consensus on rating quality of evidence and strength of recommendations. BMJ 2008, 336:924-926.

33. Dumas F, Grimaldi D, Zuber B, Fichet J, Charpentier J, Pène F, Vivien B, Varenne O, Carli P, Jouven X, Empana JP, Cariou A: Is hypothermia after cardiac arrest effective in both shockable and nonshockable patients?: insights from a large registry. Circulation 2011, 123:877-886.

34. Storm C, Nee J, Roser M, Jorres A, Hasper D: Mild hypothermia treatment in patients resuscitated from non-shockable cardiac arrest. Emerg Med J 2012, 29:100-103.

35. Lundbye JB, Rai M, Ramu B, Hosseini-Khalili A, Li D, Slim HB, Bhavani SP, Nair $\mathrm{SU}$, Kluger J: Therapeutic hypothermia is associated with improved neurologic outcome and survival in cardiac arrest survivors of nonshockable rhythms. Resuscitation 2012, 83:202-207.

36. Arrich J, Holzer M, Herkner H, Mullner M: Hypothermia for neuroprotection in adults after cardiopulmonary resuscitation. Cochrane Database Syst Rev 2009, CD004128.

37. Derwall M, Stoppe C, Brucken D, Rossaint R, Fries M: Changes in S-100 protein serum levels in survivors of out-of-hospital cardiac arrest treated with mild therapeutic hypothermia: a prospective, observational study. Crit Care 2009, 13:R58.

38. Rittenberger JC, Guyette FX, Tisherman SA, DeVita MA, Alvarez RJ, Callaway CW: Outcomes of a hospital-wide plan to improve care of comatose survivors of cardiac arrest. Resuscitation 2008, 79:198-204.

39. Gaieski DF, Band RA, Abella BS, Neumar RW, Fuchs BD, Kolansky DM Merchant RM, Carr BG, Becker LB, Maquire C, Klair A, Hylton J, Goyal M: Early goal-directed hemodynamic optimization combined with therapeutic hypothermia in comatose survivors of out-of-hospital cardiac arrest. Resuscitation 2009, 80:418-424.

doi:10.1186/cc12524

Cite this article as: Sandroni $C$, et al.: Therapeutic hypothermia: is it effective for non-VF/VT cardiac arrest? Critical Care 2013, 17:215 